\title{
Acknowledgement of Financial Support
}

\section{Caries Research}

During 2009, ORCA has continued to receive generous financial support from both charitable bodies and from commercial organisations. This has enabled ORCA to carry out its work in education and in stimulation of caries research. Support from Gaba International, Mars, 3M ESPE and Unilever enables ORCA to run its Summer Schools and Symposia, and to distribute additional copies of the abstracts issue of Caries Research. ORCA is very pleased to give warm thanks to all its charitable and corporate members for their valuable support. Thanks also go to the Zsolnay porcelain factory, who donate the ORCA-Zsolnay Prize.

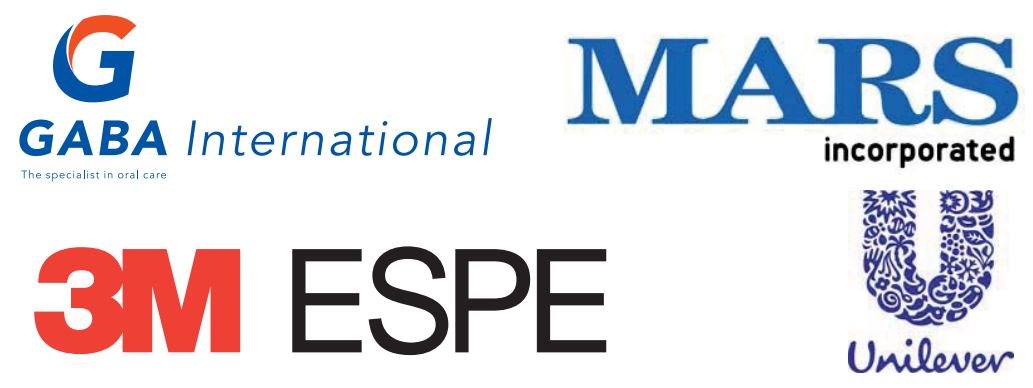

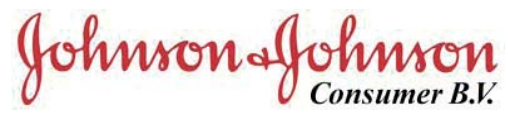

Colgate Palmolive
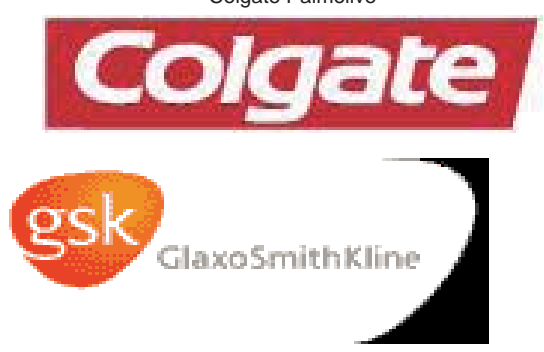

Informationskreis

Mundhygiene und Ernährungsverhalten

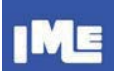

Coca-Cola

Lion Corporation

Mibelle AG

Cosmetics

(N)

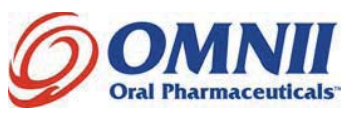

PHILIPS

Sarafee

Household

\& Body Care

Procters Gamble

ORAL HEALTHCARE

Wm. WRIGLEY Jr. Company
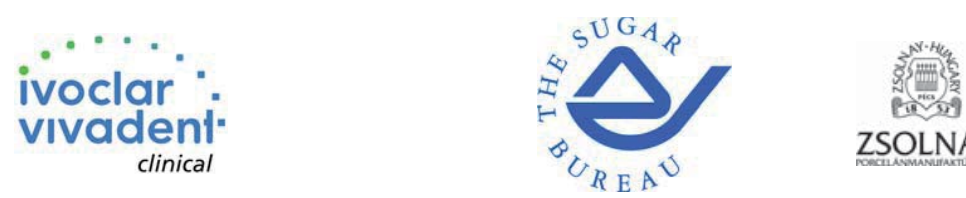

ZSOLNAY 
Filename: cre000

Article-No: 000, Fig.: 0, Tab.: 0

$<$ Issueid $>006<$ /Issueid $>$

\section{Abstract}

Sorry, there is no abstract. 